\title{
Isolation and Identification of 9-methylgermacrene-B as the Putative Sex Pheromone of Lutzomyia cruzi (Mangabeira, 1938) (Diptera: Psychodidae)
}

\author{
Reginaldo P Brazil/+,JGC Hamilton*
}

\author{
Laboratório de Leishmanioses, Centro de Pesquisas Rene Rachou-Fiocruz, Av. Augusto de Lima 1715, 30190-002 Belo \\ Horizonte, MG, Brasil *Chemical Ecology Group, Centre for Applied Entomology and Parasitology, \\ University of Keele, England
}

Lutzomyia (Lutzomyia) cruzi has been named as a probable vector of Leishmania chagasi in Corumbá, Mato Grosso do Sul, Brazil. Taxonomically L. cruzi is closely related to the L. longipalpis species complex. Females of L. cruzi and L. longipalpis are morphologically indistinguishable and associated males must be examined carefully to confirm identifications. Chemical analysis hexane extracts of male L. cruzi has revealed the presence of a 9methylgermacrene-B (C16), a homosesquiterpene ( $m w 218$ ) previously shown to be the sex pheromone of one of the members of the L. longipalpis species complex.

Key words: Phlebotominae - Lutzomyia cruzi - sex pheromone - 9-methylgermacrene-B

The sand fly Lutzomyia cruzi (Mangabeira) has been named as a probable vector of Leishmania chagasi (Kinetoplastida: Trypanosomatidae), the causative agent of visceral leishmaniasis in the State of Mato Grosso do Sul in central Brazil (Santos et al. 1998). L. cruzi is closely related to the L. longipalpis (Lutz \& Neiva) species complex, both belong to the subgenus Lutzomyia and are members of the same series (longipalpis) (Martins et al. 1978, Young \& Duncan 1994). The females of L. cruzi and $L$. longipalpis are morphologically indistinguishable and associated males should be examined carefully to provide accurate species identification.

Field and laboratory observations have shown that prior to copulation L. cruzi males wing flutter, behaviour that may possibly be associated with pheromone release in male sand flies of other species. Previous studies on male $L$. cruzi have shown that potential pheromone-disseminating structures are visible, as a pair of pale patches, on the fourth tergite (Spiegel et al. 1998) and are similar in appearance to those seen in the L. longipalpis complex (Mangabeira 1969). The patches are typically characterised by numerous small papules associated with underlying secretory tissue. They are the confirmed site of sex pheromone production in the L. longipalpis complex (Morton \& Ward 1989, Ward et al.1993, Hamilton et al.1994) and a suspected site of sex pheromone production in other Neotropical sand flies (Hamilton \& Ward 1994, Hamilton et al. 1999a).

Financial support: CNPq (Pronex), Papes

${ }^{+}$Corresponding author. Fax:+55-31-3295.3115. E.mail:

rpbrazil@cpqrr.fiocruz.br

Received 28 June 2001

Accepted 3 October 2001
The sex pheromones of the L. longipalpis species complex have been shown to be novel homosesquiterpenes (C16) or a diterpene (C20). The homosesquiterpenes have been characterised as 3-methyl- $\alpha$-himachalene (found in L. longipalpis from Jacobina, State of Bahia, Brazil) and (S)-9-methylgermacrene-B (found in L. longipalpis from Lapinha Cave, State of Minas Gerais, Brazil) (Hamilton et al. 1996a,b, 1999b,c). The diterpene is a cembrene and is found typically in L. longipalpis from Sobral (State of Ceará, Brazil) (JCG Hamilton unpublished). These compounds act as sex pheromones and are attractants for conspecific females and may help to maintain species isolation (Roelofs \& Comeau 1969, Hamilton et al. 1994). The objective of this study was to collect preliminary information on the putative structure of the sex pheromone of $L$. cruzi.

L. cruzi were collected with CDC light traps in a chicken coop in Corumbá, Mato Grosso do Sul (1859'44"S and 57'39'16W). After separating males from females and checking species identities, males of $L$. cruzi were placed in glass ampoules prepared from Pasteur pipettes with nhexane $(20 \mu \mathrm{l})$ (spectroscopic grade, Sigma Co.) and flame sealed. Prior to analysis, extracts were removed from the Pasteur pipette vials, filtered through glass wool to remove the flies and fly hairs, and the volume reduced un$\operatorname{der} \mathrm{N}_{2}$ to $1 \mu \mathrm{l}$. All the chemical analysis was done according to the procedures of Hamilton et al. (1999a). Six individual males were examined. Mass spectra and gas chromatography retention times were compared with authentic 9-methylgermacrene-B. Peak enhancement studies were performed by coinjecting extracts of $L$. longipalpis from Lapinha and L. cruzi. GC-MS analysis was carried out on a Hewlett Packard 5890 II+ gas chromatograph with an HP-5MS capillary column, $30 \mathrm{~m} \times 0.25 \mathrm{~mm}$ i.d., $0.25 \mathrm{~mm}$ film thickness, directly coupled to a Hewlett Packard 5972A benchtop mass spectrometer, EI, $70 \mathrm{eV}, 165^{\circ} \mathrm{C}$. Sample was 
introduced via an on-column injector $\left(40^{\circ} \mathrm{C}\right)$. The gas chromatograph (GC) was temperature programmed with an initial $2 \mathrm{~min}$ at $40^{\circ} \mathrm{C}$, then an increase of $10^{\circ} \mathrm{C} \mathrm{min}^{-1}$ to a final isothermal period at $250^{\circ} \mathrm{C}(10 \mathrm{~min})$.

The mass spectral, retention time and peak enhancement results showed that $L$. cruzi males produce 9methylgermacrene- $\mathrm{B}$. The finding of the presence of 9methylgermacrene-B in L. cruzi males confirms the close taxonomic relationship between $L$. cruzi and $L$. longipaplis. However 9-methylgermacrene-B can occur in number of different isomeric forms and in L. longipalpis from Lapinha it occurs as the $(S)$ form. The isomeric form of 9-methyl-germacrene-B from $L$. cruzi has not yet been determined.

L. cruzi is found only in central Brazil and as far as we are aware does not occur sympatrically with L. longipalpis for the majority of its distribution. It would be interesting in the future to determine the role of 9-methylgermacrene$\mathrm{B}$ as a sex pheromone and how it maintains species isolation in L. cruzi.

\section{REFERENCES}

Hamilton JGC, Ward RD 1994. Chemical analysis of a putative sex pheromone from Lutzomyia pessoai (Diptera: Psychodidae). Ann Trop Med Parasitol 88: 405-412.

Hamilton JGC, Brazil RP, Morgan ED, Alexander B 1999a. Chemical analysis of oxygenated homosesquiterpenes: a putative sex pheromone from Lutzomyia lichyi (Diptera: Psychodidae). Bull Entom Res 89: 139-145.

Hamilton JGC, Dawson GW, Pickett JJ 1996a. 9-Methylgermacrene-B, a novel homosesquiterpene from sex pheromone glands of Lutzomyia longipalpis (Diptera: Psychodidae) from Lapinha, Brazil. J Cheml Ecol 22: 1477-1491.

Hamilton JGC, Dawson GW, Pickett JJ 1996b. 3-Methy- $\alpha$ himachalene; sex pheromone of Lutzomyia longipalpis (Diptera: Psychodidae) from Jacobina, Brazil. J Chem Ecol 22: 2331-2340.

Hamilton JGC, Dougherty MJ, Ward RD 1994. Sex phero- mone activity in a single component of tergal gland extract of Lutzomyia longipalpis (Diptera: Psychodidae) from Jacobina, northeastern Brazil. J Chem Ecol 20: 141-151.

Hamilton JGC, Hooper AM, Mori K, Pickett JA, Sano S 1999b. 3 -Methyl- $\alpha$-himachalene confirmed, and the relative stereochemistry defined, by synthesis as the sex pheromone of the sandfly Lutzomyia longipalpis from Jacobina, Brazil. Chem Comm 4: 355-356.

Hamilton JGC, Ibbotson HC, Hooper AM, Mori K, Pickett JA, Sano S 1999c. 9-Methylgermacrene-B confirmed by synthesis as the sex pheromone of the sandfly Lutzomyia longipalpis from Lapinha, Brazil, and the absolute stereochemistry defined as 9S. Chem Comm 8: 2335-2336.

Martins AV, Williams P, Falcão AL 1978. American Sandflies Diptera: Psychodidae: Phlebotominae), Academia Brasileira de Ciencias, Rio de Janeiro, 195 pp.

Mangabeira O 1969. Sôbre a sistematica e biologia dos Phlebotomus do Ceará. Rev Bras Malariol D Trop 21: 3-25.

Morton IA, Ward RD 1989. Laboratory response of female Lutzomyia longipalpis sandflies to a host and male pheromone source over distance. Med Vet Entomol 3: 219-223.

Roelofs WL, Comeau A 1969. Sex pheromone specificity: taxonomic and evolutionary aspects in Lepidoptera. Science 165: 398-400.

Santos SO, Arias J, Ribeiro AA, Hoffman MP, Freitas RA, Malacco MAF 1998. Incrimination of Lutzomyia cruzi as a vector of American visceral leishmaniasis. Med Vet Entomol 12: 315-317.

Spiegel CN, Brazil RP, Santos SO, Soares MJ 1998. Morphology of pheromone gland pores in male Lutzomyia cruzi insects (Diptera: Psychodidae). Mem Inst Oswaldo Cruz. 93 (Suppl.): 338.

Ward RD, Hamilton JGC, Dougherty MJ, Falcão AL, Feliciangeli MD, Perez JE, Veltkamp CJ 1993. Pheromone disseminating structures in males of the sub-family Phlebotominae (Diptera: Psychodidae). Bull Entomol Res 83: 1-9.

Young DG, Duncan MA 1994. Guide to the identification and geographic distribution of Lutzomyia sandflies in Mexico, the West Indies, Central and South America (Diptera: Psychodidae). M Amer Entomol Inst 54: 1-881. 